\title{
Investigation of flow-rainfall co-variation for catchments selected based on the two main sources of River Nile
}

Article in Stochastic Environmental Research and Risk Assessment · February 2017

DOI: $10.1007 /$ s00477-017-1397-9

CITATIONS

0

2 authors:

Charles Onyutha

24 PUBLICATIONS 90 CITATIONS

SEE PROFILE
READS

32

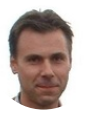

Patrick Willems

University of Leuven

437 PUBLICATIONS $\quad$ 4,207 CITATIONS

SEE PROFILE

Some of the authors of this publication are also working on these related projects:

Project

BRIGAID - Bridging the Gap for Innovations in Disaster Resilience (EU H2020 Innovation call project) View project 


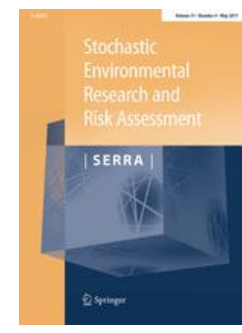

\title{
Investigation of flow-rainfall co-variation for catchments selected based on the two main sources of River Nile
}

\author{
Charles Onyutha $^{* 1,2}$, Patrick Willems ${ }^{1}$ \\ ${ }^{1}$ Hydraulics Laboratory, KU Leuven, Kasteelpark Arenberg 40, 3001 Leuven, Belgium \\ ${ }^{2}$ Faculty of Technoscience, Muni University, P.O. Box 725, Arua, Uganda \\ *Corresponding Author (Charles Onyutha); E-Mail: conyutha@gmail.com
}

ABSTRACT

The co-variation of rainfall and flow was assessed in four selected catchments of the River Nile which has two main sources including the White Nile (in the Equatorial region) and the Blue Nile (from the Ethiopian highlands). The selected catchments included Kyoga and Kagera (from the Equatorial region), as well as Blue Nile and Atbara (in Sudan and Ethiopia). In each catchment, the flow-rainfall co-variation was investigated at both seasonal and annual time scales. To explain aggregated variation at larger temporal scale while investigating the possible change in catchment behavior, which may interfere with the flow-rainfall relationship, rainfall-runoff modeling was done at daily time scale using data (falling within the period 1949-2003) from Kagera and Blue Nile i.e. the major catchment of each region where the River Nile emanates. Correlation analysis was conducted to assess how well the variation of flow and that of catchment-wide rainfall resonate. The co-occurrence of the changes in observed and simulated overland flow was examined using the Quantile Perturbation Method (QPM). Trends in the model residuals were detected using the Mann-Kendal (MK) and Cumulative Rank Difference (CRD) tests. The null hypothesis $H_{0}$ (no correlation between rainfall and flow) was rejected at the significance level $\alpha$ of $5 \%$ for all the selected catchments. The temporal changes in terms of the QPM anomalies for both the observed and simulated flow were in a close agreement. The evidence to reject the $H_{0}$ (no trend in the model residuals) was generally statistically insufficient at $\alpha=5 \%$ for all the models and selected catchments considering both the MK and CRD tests. These results indicate that change in catchment behavior due to anthropogenic influence in the Nile basin over the selected time period was minimal. Thus, the overall rainfall-runoff generation processes of the catchments did not change in a significant way over the selected data period. The temporal flow variation could be attributed mainly to the rainfall variation.

Keywords: Rainfall-Runoff Modeling; CRD Trend Test; VHM; NAM; HBV; River Nile; QPM

\section{Journal home page}

Stochastic Environmental Research and Risk Assessment: https://link.springer.com/journal/477

\section{Author manuscript}

The content of this article which begins on the next page is identical to the content of the published paper but without copyediting, typesetting and review of the resulting proof before the final version of the paper. Please know that some errors could be discovered during the production process and may slightly alter the content of the paper.

\section{How to Cite}

Onyutha C, Willems P (2017) Investigation of flow-rainfall co-variation for catchments selected based on the two main sources of River Nile. Stochastic Environmental Research and Risk Assessment, doi: $10.1007 / \mathrm{s} 00477-017-1397-9$

\section{Published version}

http://dx.doi.org/10.1007/s00477-017-1397-9 (first online on the 21 February 2017) 
The Nile basin faces many formidable challenges some of which include: flood and drought conditions due to climate variability, restive trans-boundary water management issues, widespread poverty, high demographic growth rates, food insecurity resulting from combined effects of rainfall variability and the unswerving dependence of majority of the population on subsistence and rain-fed agriculture, etc. To deal with these challenges, careful planning and management of the River Nile water resources is required. One form of support to such requirement is the enhanced comprehension of the historical patterns of flow variation and their spatial differences across the entire Nile basin as done in this study. So far, several investigations were made on the variability of flow and hydro-climatic variables for the Nile basin.

Although the variation of river flow in the Nile basin may be ascribed to the changes in rainfall, a number of studies based on remotely sensed land cover or satellite data (see e.g. Elmqvist, 2005; Rientjes et al., 2011) or aerial photographs (Bewket and Sterk, 2005) have reported on the effects of anthropogenic factors on river flow regimes. According to Rientjes et al. (2011), forest cover decreased from 50 to $16 \%$ in the Gilgel Abay catchment in the Lake Tana basin over the period 1973-2001. Elmqvist (2005) noted that the cropland per household reduced from 0.4 to $0.1 \mathrm{~km}^{2}$ over the period 1969-2002 in Sararya Makawi, Sudan. Bewket and Sterk (2005) concluded on an increase in cultivation area in the Chemoga catchment for the period between 1960 and 1999. Flow changes were in these studies attributed to the land use changes. Bewket and Sterk (2005), for instance, related the identified decrease of $0.6 \mathrm{~mm} / \mathrm{year}$ in the Chemoga catchment flow during the dry season (October to May) between 1960 and 1999 to the increase in cultivation area. The main problem with such flow change attribution studies is that for an accurate analysis, archives are required of aerial photos or satellite images of land cover with high spatial and temporal resolutions and with good quality for long-term periods. Such archives are difficult to obtain for the study area. To partly meet the limitation of such archives, some studies complemented the available land use and cover data from satellite images with catchment hydrological modeling. The effect of the change in catchment characteristics on the watershed hydrology can indeed be investigated using hydrological models, by preference to fully distributed process-based models. However, the input data required by such detailed hydrological models are of large amount. Besides, due to their structural complexity and over-parameterization, the parameters of such models are difficult to optimally estimate. Alternatively, conceptual models that are more parsimonious, hence with fewer parameters than the physically-based models, can be applied to assess changes in catchment response in a meteorological-river flow data-based way, but at a lumped catchment scale. Such modeling studies were conducted by Mango et al. (2011), and Olang and Fürst (2011) for the equatorial region; Legesse et al. (2003, 2004), Bewket and Sterk (2005), Rientjets et al. (2011), and Gebrehiwot et al. (2013) for Ethiopia. Based on the land-use scenario investigation using the Soil and Water Assessment Tool, Mango et al. (2011) concluded for the Mara catchment that the magnitude of the extreme low/high flow would reduce/increase if the conversion of forests to agriculture and grassland in the headwaters of the catchment continued. Olang and Fürst (2011) used the HEC-HMS rainfall-runoff model to investigate the effect of the land-use changes over the period between 1973 and 2000 on the hydrology of the Nyando catchment. The authors found an increase of $16 \%$ in the peak discharges over the entire period considered. Using the PRMS model, Legesse et al. (2003) found that flow would reduce to about $8 \%$ if the dominantly cultivated/grazing land of South Central Ethiopia was to be converted to woodland. Similarly for Lake Abiyata, Legesse et al. (2004) noted a remarkable mismatch between the observed and PRMS-modeled lake level over the period 1984-1996 compared with that for 1968-1983. The authors ascribed this discrepancy to human influence on the lake in terms of the direct use of the influent rivers. By dividing the time series over the period 1960-2004 into three parts based on either the political and 
land management policy changes, Gebrehiwot et al. (2013) applied the HBV model to investigate the effect of land-use changes on the runoff flow in the Birr, Upper-Didesa, Gilgel Abbay, and Koga catchments of the Blue Nile basin. According to the authors, although six out of nine parameters of the HBV model changed significantly over the three periods during the rainfall-runoff modeling, the integrated functioning of the watersheds showed minimal changes.

The problem with the above studies each of which applied only one hydrological or rainfall-runoff model lies in the lack of insight about the influence of model selection on the conclusive flow variation attribution. It was recently remarked by Onyutha (2016a) that the influence of hydrological model selection leads to large under- or over-estimation of simulated extreme flow events which are so relevant for careful analyses as in this study. Moreover, based on the model complexity and set of parameters for calibration, the judgment of the confidence in the selection of a particular model to investigate the effect of land-use change on the flow variation is not a simple task. Other factors such as the change in meteorological conditions need to be addressed as well. Studies by Abtew et al. (2009), Camberlin (1997), Taye and Willems (2013), and Tierney et al. (2013), gave evidence that the variability in hydro-climatic variables such as rainfall over the study area can be explained by the variation in large-scale ocean-atmosphere interactions.

In this study, because of the data limitation and quality problem for rainfall-runoff modeling in the Nile basin, three rainfall-runoff models NAM (Danish Hydraulic Institute DHI, 2007; Madsen, 2000), HBV (Bergström, 1976; AghaKouchak and Habib, 2010; AghaKouchak et al., 2013) and VHM (Willems, 2014; Willems et al., 2014) were applied. These three models were adopted in this study because they have been recently used by Taye and Willems (2013) (for NAM and VHM), and Gebrehiwot et al. (2013) (for HBV) to successfully investigate the effect of meteorological and catchment rainfall-runoff response changes on the flow regimes in the study area. However, in some of these previous studies, manual calibration which is known to be subjective was adopted. To limit the influence of subjectivity in the model calibration process and address the models' uncertainties, the Generalized Likelihood Uncertainty Estimation (GLUE) of Beven and Binley (1992) was adopted in this study. The model-based findings moreover were complemented with the analyses of temporal variation in overland flow and trends in the model residuals to support the hypothesis of flow variation attribution. In explaining the identified trends and temporal variation, special attention was given to the co-variation of flow and rainfall. The final goal was to provide new insights in the spatiotemporal variation of flow along the main River Nile. To do so while taking into account the regional differences in the flow variation from the two main sources of the River Nile, a total of four catchments were considered. The selected catchments included Kyoga and Kagera (from the White Nile region), as well as Blue Nile and Atbara (in the Central region mainly drained by the Blue Nile). As opposed to the previous flow variation attribution studies which were mostly limited to catchment scale, the insight from considering the regional differences as in this study is vital for regional planning of water resources of the River Nile.

More specifically, this study aimed at: 1) investigating the co-variation of flow and rainfall, and 2) rainfall-runoff modeling to investigate the evidence of changes in rainfall-flow catchment response behavior. The modeling was done at daily time scale in order to explain aggregated variation at larger temporal scale.

\section{$2 \quad$ Study area and data}

\subsection{General description of the main River Nile basin}

As one of the longest rivers in the world, River Nile goes through a long journey of $6,695 \mathrm{~km}$ from its furthest source (Ruvyironza in Kagera catchment) to the Nile Delta in Egypt. The drainage area 
of the River Nile with the coverage from $31^{\circ} \mathrm{N}$ to $4^{\circ} \mathrm{S}$ (in north-south direction) and $24^{\circ}$ to $40^{\circ} \mathrm{E}$ (in west-east direction) is about $3,400,000 \mathrm{~km}^{2}$ (Figure 1). The lakes within the River Nile basin include the Victoria, Edward, Kyoga, Albert, No, Tana, and Nasser. There are two main sources of the River Nile including the White Nile (from the equatorial region), and the Blue Nile (from the Ethiopian highlands). The percentage of the River Nile riparian countries covered by the Nile basin includes (Food and Agriculture Organization FAO, 1997): Uganda (98.1\%), Kenya (8.0\%), Tanzania (8.9\%), Rwanda (75.5\%), Burundi (47.6\%), Democratic Republic of Congo (0.9\%), Sudan and South Sudan (79.0\%), Ethiopia (33.2\%), Eritrea (20.4\%), and Egypt (32.6\%). The River Nile receives little or negligible runoff from about $40 \%$ of its drainage (basin) area which comprises dry lands of either arid or hyper-arid condition. Moreover, the River Nile loses about $50 \%$ of its water by evaporation in the floodplains of the Sudd region of South Sudan. The impacts of these factors result in lower runoff efficiency in the Nile basin despite its vast drainage area. Eventually, when the low runoff volume is divided by the large rainfall volume, a small runoff coefficient is obtained.

\subsection{Selected catchments of the River Nile}

For this study, four catchments including Kagera, Kyoga, Blue Nile and Atbara were selected from the Nile basin (Figure 1). Brief descriptions of the catchments are given below.

River Kagera catchment located between the Lakes of Victoria, Tanganyika and Kivu has a drainage area of about $60,000 \mathrm{~km}^{2}$ and streches into four contries of East Africa including Burundi, Rwanda, Tanzania, and Uganda. The basin stretches in the north-south direction from $0^{\circ} 45^{\prime}$ to $3^{\circ} 35^{\prime} \mathrm{S}$ and in the east-west direction from $29^{\circ} 15^{\prime}$ to $30^{\circ} 51^{\prime} \mathrm{E}$. From the drainage area $184,000 \mathrm{~km}^{2}$ of the Lake Victoria basin, River Kagera has the largest drainage area compared to other catchments.

The Lake Kyoga which is shallow and situated at the mean elevation of 1,033 m receives flow from the Victoria Nile and the tributaries in the Mount Elgon region. Within the Great Lakes region, Lake Kyoga (though not a great lake itself) acts as an important connection between the two lakes Albert and Victoria with respect to the River Nile flow. Lake Kyoga catchment with the drainage area of about $57,000 \mathrm{~km}^{2}$ stretches between $0^{\circ} 20^{\prime}$ and $3^{\circ} 40^{\prime} \mathrm{N}$ (in the north-south direction) and $32^{\circ} 10^{\prime}$ and $34^{\circ} 50^{\prime} \mathrm{E}$ (in the east-west direction). The eastern boundary of the Lake Kyoga drainage area runs along the Uganda-Kenya border.

The Blue Nile catchment with its outlet situated around the Tuti island between Omdurman and Khartoum North has a drainage area of about $325,000 \mathrm{~km}^{2}$. The Blue Nile with a total length of about 1,460 km flows into and out of Lake Tana and emanates from the Ethiopian highlands based on the two main tributaries including the Dinder and Rahad rivers.

The Atbara catchment which is about $202,650 \mathrm{~km}^{2}$ strethes in the east-west direction between $33^{\circ} 45^{\prime}$ to $39^{\circ} 45^{\prime} \mathrm{E}$ and in the north-south direction between $11^{\circ} 30^{\prime}$ to $18^{\circ} 55^{\prime} \mathrm{N}$. The watershed consists of the $880 \mathrm{~km}$-long River Atbara which is the last tributary of the River Nile. The River Atbara which joins the main Nile about $320 \mathrm{~km}$ downstream of Khartoum, has a number of tributaries a few of which include Tekeze, Bahar El Salam, Setit, etc. 


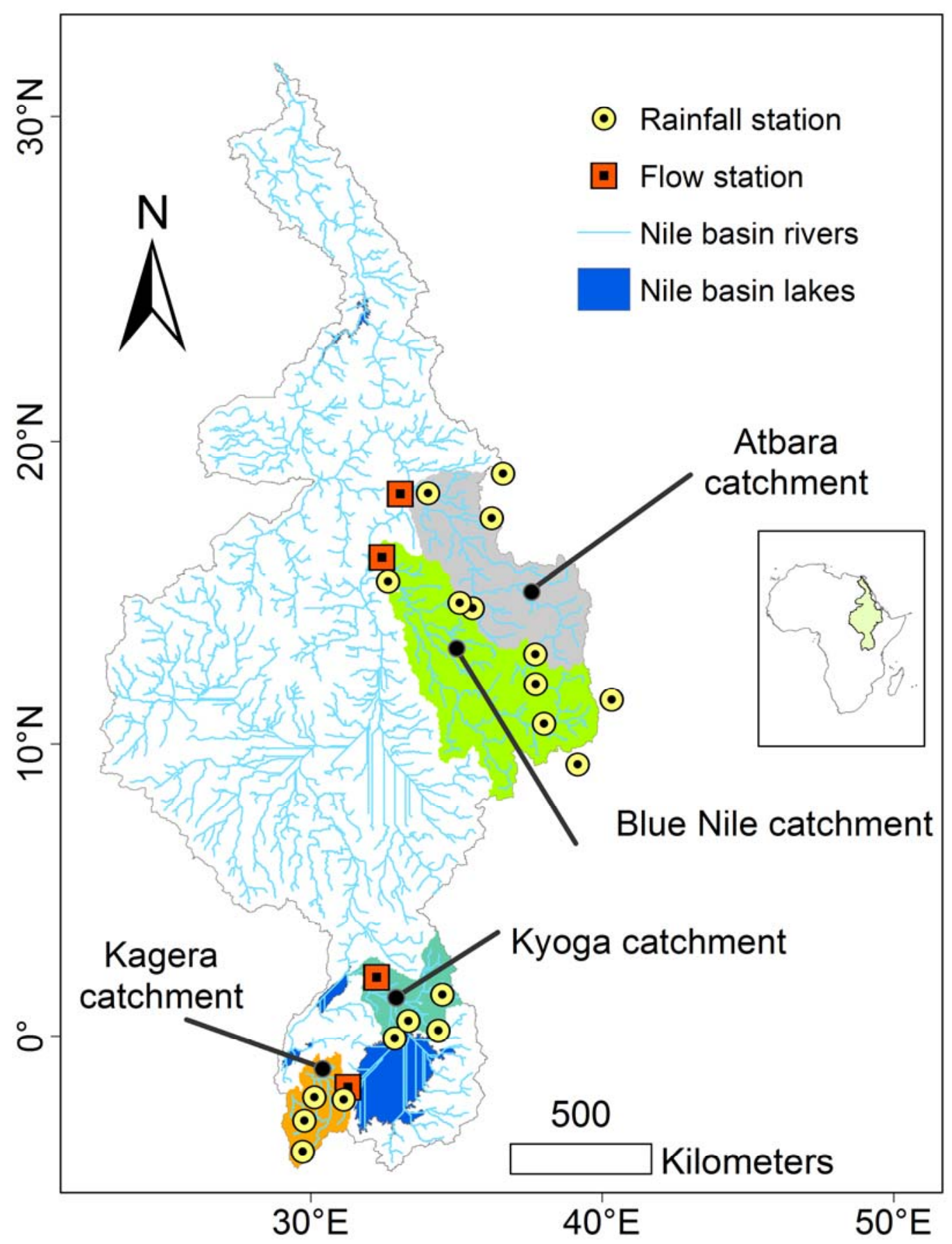

Figure 1 Selected catchments with locations of hydrological and meteorological stations (see Tables 1 and 2 for details) in the Nile basin.

\subsection{River flow data}

River flow data recorded at the outlet of the four selected catchments (see Table 1) in the Nile basin were obtained from various sources. The flow data at some stations were of both daily and monthly time scales. Monthly flow series for Stations 1, 3 and 4 for the periods 1940-1971, 1902-1982, and 1912-1982 respectively were obtained from the Global Runoff Data Centre (GRDC), Koblenz, Germany. Monthly flow series covering the period 1950-2000 for Station 2 was obtained from the 
report by Kennedy \& Donkin Power Ltd (1997). The monthly series were converted to annual time scale. The long-term average (AF) and coefficient of variation $\left(C_{\mathrm{v}}\right)$ in the last two columns of Table 1 were computed using the annual flow. The monthly flow series were used for assessing their covariation with rainfall. However, daily data were used for rainfall-runoff modeling.

Daily flow data from 1950 to 1986 for station 1 as previously used by Onyutha and Willems (2015a) was obtained at KU Leuven from the database of the River Nile basin Flow Regimes from International, Experimental and Network Data (FRIEND/Nile) project (http://www.unesco.org/new/en/cairo/natural-sciences/hydrology-programme/friendnile/ [accessed $10^{\text {th }}$ September, 2014]). For station 3, daily flow data from 1965 to 2002 were obtained based on personal connection. The monthly series of the said data used for the assessment of flow-rainfall covariation is provided as a supplementary material to this paper (see Sup_1). To check the similarity in variation of the data obtained from two sources but for the same station, the daily series were converted to monthly time scale for testing the null hypothesis $H_{0}$ (no correlation). Based on common periods of the monthly data from the two sources, i.e. 1965-1982 and 1950-1971 for the flow at Khartoum and Kyaka Ferry, the coefficients of correlation were 0.98 and 0.93 which were greater than the critical values (at the significance level $\alpha$ of $0.1 \%$ ) of 0.15 and 0.20 respectively. Thus, the $H_{0}$ (no correlation between two datasets at the same station) was rejected at $\alpha$ of $0.1 \%$ for each of the stations.

Table 1 Overview of the selected hydrological stations and flow data

\begin{tabular}{llllcccc}
\hline $\begin{array}{l}\text { St. } \\
\text { no. }\end{array}$ & Name & $\begin{array}{c}\text { Nile } \\
\text { Region }\end{array}$ & Country & $\begin{array}{c}\text { Long. } \\
{\left[{ }^{\circ}\right]}\end{array}$ & $\begin{array}{c}\text { Lat. } \\
{\left[{ }^{\circ}\right]}\end{array}$ & $\begin{array}{c}\mathrm{AF} \\
{\left[\mathrm{m}^{3} / \mathrm{s}\right]}\end{array}$ & $\begin{array}{c}C_{\mathrm{v}} \\
{[-]}\end{array}$ \\
\hline 1 & Kyaka Ferry & L. Vict. basin & Tanzania & 31.42 & -1.27 & 194 & 0.35 \\
2 & Kamdini & Kyoga Nile & Uganda & 32.33 & 2.24 & 1075 & 0.31 \\
3 & Khartoum & Blue Nile & Sudan & 32.51 & 15.64 & 1564 & 0.22 \\
4 & Kilo 3 & Atbara & Sudan & 33.99 & 17.68 & 385 & 0.35 \\
\hline \multicolumn{2}{l}{ L. Vict. : Lake Victoria; } & Long. : Longitude; & Lat. : Latitude; & & \\
\hline
\end{tabular}

\subsection{Rainfall data}

Data from several meteorological stations were used in this study. The daily rainfall data at 5 locations over the Blue Nile were those used in a study by Taye and Willems (2013). Daily rainfall at 4 locations over the Kagera catchment, and monthly rainfall series at 6 stations in and around Atbara catchment were obtained from the FRIEND/Nile project. Furthermore, daily rainfall data from 4 stations in the Kyoga basin were obtained from the Ministry of Water and Environment, Uganda. Especially for the last two data sources, missing rainfall data records were in-filled (using the inverse distance weighted interpolation technique) in a similar way as done for a number of meteorological stations of the Nile basin in previous studies by Onyutha and Willems (2015b, c).

Table 2 shows location and ID of each selected station as well as the data period and long-term rainfall statistical metrics $C_{\mathrm{v}}$, skewness $\left(C_{\mathrm{s}}\right)$ and actual excess kurtosis $\left(C_{\mathrm{k}}\right)$ computed using series of monthly time scale. Values of $C_{\mathrm{s}}$ and $C_{\mathrm{k}}$ greater than zero indicate that the distribution of the data deviate from the Gaussian type. The values of $C_{\mathrm{v}}$ in Kyoga and Kagera were lower than those of Atbara and Blue Nile. The highest values of $C_{\mathrm{v}}, C_{\mathrm{s}}$ and $K_{\mathrm{s}}$ were obtained for stations in the Atbara catchment. This is because the catchment is located in an arid climate region and thus the data were characterized by large extent of ties caused by the existence of zeros in the series. Moreover, the data from Atbara had larger differences between the minimum and maximum monthly rainfall totals than for other selected catchments. 
Table 2 Rainfall stations for selected watersheds

\begin{tabular}{ll|cc|cc|ccc}
\hline & Station & \multicolumn{2}{c|}{ Location } & \multicolumn{2}{c}{ Data period } & \multicolumn{3}{c}{ Statistical metric } \\
Paper ID & \multicolumn{1}{c}{ Name } & Long. & Lat. & From & To & $C_{\mathrm{k}}[-]$ & $C_{\mathrm{s}}[-]$ & $C_{\mathrm{v}}[-]$ \\
\hline \multicolumn{7}{c}{ Kagera } \\
\hline Kag1 & Mugera (Paroisse) & 29.97 & -3.32 & 1940 & 1990 & 0.98 & 0.73 & 0.78 \\
Kag2 & Muyinga & 30.35 & -2.85 & 1940 & 1992 & -0.17 & 0.44 & 0.72 \\
Kag3 & Igabiro Estate & 31.55 & -1.82 & 1940 & 1994 & 0.47 & 0.78 & 0.80 \\
Kag4 & Musenyi (Paroisse) & 30.03 & -2.97 & 1940 & 1994 & 1.34 & 1.06 & 0.83 \\
\hline \multicolumn{7}{c}{ Atbara } \\
\hline Atb1 & Atbara & 33.97 & 17.70 & 1907 & 1995 & 36.39 & 5.18 & 3.06 \\
Atb2 & Ungwatiri & 36.00 & 16.90 & 1950 & 1981 & 22.60 & 4.26 & 2.66 \\
Atb3 & Abu-Quta & 32.70 & 14.88 & 1948 & 1987 & 8.65 & 2.81 & 2.06 \\
Atb4 & Haiya & 36.37 & 18.33 & 1950 & 1981 & 33.39 & 5.10 & 2.67 \\
Atb5 & Gedaref & 35.40 & 14.03 & 1903 & 1996 & 3.07 & 1.78 & 1.50 \\
Atb6 & Ghadambaliya & 34.98 & 14.20 & 1948 & 1988 & 3.88 & 1.95 & 1.65 \\
\hline \multicolumn{7}{c}{ Blue Nile } \\
\hline Blu1 & Bahr Dar & 37.41 & 11.60 & 1964 & 2004 & 0.95 & 1.36 & 1.30 \\
Blu2 & Debremarcos & 37.67 & 10.33 & 1964 & 2004 & -0.46 & 0.86 & 1.00 \\
Blu3 & Gonder & 37.40 & 12.55 & 1964 & 2004 & 1.54 & 1.44 & 1.21 \\
Blu4 & Addis Ababa & 38.75 & 09.03 & 1964 & 2004 & -0.06 & 0.95 & 1.02 \\
Blu5 & Kombolcha & 39.83 & 11.10 & 1964 & 2004 & 2.32 & 1.56 & 1.11 \\
\hline & & \multicolumn{7}{c}{ Kyoga } \\
\hline Kyo1 & Imanyiro & 33.27 & 0.29 & 1950 & 1977 & 3.51 & 1.34 & 0.65 \\
Kyo2 & Kapchorwa & 34.43 & 1.24 & 1950 & 1995 & 3.07 & 1.15 & 0.69 \\
Kyo3 & Buwabwale & 34.21 & 0.54 & 1950 & 1977 & 4.73 & 1.61 & 0.69 \\
Kyo4 & Ivukula & 33.35 & 0.57 & 1950 & 1997 & 2.12 & 1.24 & 0.68 \\
\hline
\end{tabular}

\subsection{Air temperature data}

Due to lack of long-term evaporation and temperature data from the study area, reanalysis series were deemed suitable to estimate the daily potential evapotranspiration (PET) for rainfall-runoff modeling. For both catchments (Kagera and Blue Nile) selected for investigating the change in catchment behavior through rainfall-runoff modeling, air temperature for PET estimation was required to cover the period 1950-2002. Daily air temperature could be obtained from various existing reanalysis data. However, most of the reanalysis data start after 1950 e.g. ERA-40 (from 1957 to 2002), ERA-Interim (from 1979 to present), the Japanese 55-year Reanalysis JRA-55 (from1958 to present), etc.

To obtain PET covering the entire required period 1950-2002, daily maximum $\left(T_{\max }\right)$ and minimum $\left(T_{\min }\right)$ temperature series from the Princeton Global Forcings (PGFs) (Sheffield et al., 2006) were used. The gridded $\left(0.5^{\circ} \times 0.5^{\circ}\right) T_{\max }$ and $T_{\min }$ covering the period 1948-2008 were downloaded via the link http://hydrology.princeton.edu/data/pgf/0.5deg/ [accessed: 12-02-2016]. Moreover, due to their robustness, the PGF series have been used to conduct several studies on the variability of hydrometeorological variables (see e.g. Zeng and Cai, 2016; Hoell et al., 2015). PGF series are not purely reanalysis data; however, they are derived from a combination of the NCEP-NCAR reanalysis dataset (Kalnay et al., 1996) with several other observational-based rainfall products including the TRMM, the CRU TS2.0, the GPCP, and the NASA Langley Research Center SRB. 


\subsection{Co-variation of flow and rainfall}

The variation of flow was compared with that of rainfall at both seasonal and annual time scales. In the Lake Victoria basin, two rainy seasons exist i.e. March to May (MAM) and October to December (OND) (Nicholson, 1996). The period from June to September (JJAS) is a dry season. However in the northern half (or part) of the Nile basin, JJAS is the main rainy season and the dry period runs from October through December to February (ONDJF). Consideration was given to the flow at the catchment outlet and catchment-wide weighted average rainfall based on data at stations upstream of the catchment flow outlet. A zoomed-in analysis such as that for the catchment-scale is important to obtain an insight into how strongly the micro-climate (micro-scale features) influences the flow-rainfall co-variation. For each selected catchment, comparison was made between the temporal variation of flow at the outlet of the catchment and that of: 1) rainfall at each meteorological station, and 2) catchment-wide average rainfall.

\subsection{Rainfall-runoff modeling}

Three rainfall-runoff models including NAM, VHM and HBV were applied under the same meteorological conditions in simulating daily flow at the outlets of two selected main catchments. Kagera catchment at Kyaka Ferry $\left(60,000 \mathrm{~km}^{2}\right)$ in the equatorial region and the Blue Nile catchment at Khartoum $\left(325,000 \mathrm{~km}^{2}\right)$ from Sudan and Ethiopia were selected with respect to two sources of the Nile River as already highlighted in Section 2.1.

The rainfall-runoff modeling was used to assess any possible empirical evidence for the alteration in catchment characteristics in the form of temporal change in catchment runoff response to rainfall, hence between observed and simulated flow. Explanation on this idea can be found in Section 3.3. VHM was selected because its model-structure identification and calibration approach nicely fits within the objective of this research to analyze flow and catchment changes in a data-based way. The VHM approach starts from a generalized model structure (Appendix Figure A1 a), which describes the main, lumped catchment-scale rainfall-runoff responses and processes underlying these responses. The model structure includes processes that can be identified from the available meteorological (model input) and river flow (model output) data. This data-based approach also allows identification of changes in catchment-wide responses and related processes. More specifically, Willems (2014) explains that in the VHM approach, the lumped macroscopic catchment responses are analyzed and main processes derived using a step-wise procedure including: 1) separation of observed discharge into overland flow, interflow and base flow, 2) extraction of nearly independent extremes in the form of peak over threshold events. These timeseries processing procedures can be done using the tool provided by Willems (2009). The different sub-flow components from (1) are used to identify linear or exponential relationships in the various sub-models describing the rainfall fractions contributing to the surface storage, soil moisture storage and groundwater storage. Quick flow is obtained from a combination of the overland and interflow, which are routed separately each using a single linear reservoir. The baseflow is also routed from the groundwater storage using a linear reservoir. The total runoff is obtained as the sum of the quick flow and base flow.

To take into account possible inconsistence (if any) among the models, the VHM results were, in this study, compared with those from two other, internationally well-established models NAM (DHI, 2007; Madsen, 2000) and HBV (Bergström, 1976; AghaKouchak and Habib, 2010; AghaKouchak et al., 2013) whose structures are presented in (Figure A1 b) and (Figure A1 c) 
respectively. They all consist of a number of inter-related storages for surface, soil and groundwater, relationships describing the influxes in the reservoirs, mainly depending on the timevariable relative soil saturation state (derived from the soil water storage), evapotranspiration losses, and sub-flow routing by means of linear or non-linear reservoir models. Total runoff from either HBV or NAM also comprises the combination of base flow and quick flow.

All the three models use catchment-averaged rainfall and PET as the inputs. The actual evapotranspiration is calculated by the models based on the PET and the soil water storage results. Whereas the original models (especially NAM and HBV) include snow modules, these were left out from the descriptions and application, given the location of our study area in a tropical region. Whereas catchment areas were fixed apriori, the definitions of the model parameters considered for calibration are presented in Appendix Table A1.

For each selected catchment, the catchment-wide mean areal rainfall was calculated using the Thiessen polygon method. The PET was computed using the FAO Penman-Monteith method (Allen et al., 1998) considering $T_{\min }$ and $T_{\max }$. Apart from the $T_{\max }$ and $T_{\min }$, the calculation of PET also requires humidity, radiation and wind speed. For data scarce regions e.g. the study area, the procedures for estimating the PET amidst missing data can be found in the FAO Irrigation and Drainage Paper 56. For instance, where wind speed is missing, a value of $2 \mathrm{~m} / \mathrm{s}$ can be taken as an estimate. This is on the assumption that PET is not highly sensitive to normal ranges of wind speed since the crop height of $0.12 \mathrm{~m}$ required for the reference crop is relatively small (Allen et al., 1998). More so, by assuming $T_{\min }$ to be low enough as the dew point temperature, the actual vapor pressure can be computed based on the $T_{\max }$ and $T_{\min }$ after obtaining the maximum and minimum relative humidity. Solar radiation or the shortwave radiation can be estimated from the duration of bright sunshine. Extraterrestrial radiation can be estimated as a function of latitude, date and time of day.

The calibration (validation) period of the models was 01/01/1965-31/12/1974 (01/01/1975$31 / 12 / 2002)$ for the Blue Nile, and 01/01/1950-31/12/1959 (01/01/1960-31/12/1986) for the Kagera. In other words the calibration (validation) period was 10(28) years for the Blue Nile and 10(27) years for Kagera. Model calibration strategy which also incorporates the uncertainty estimation technique was required for changing the model parameters. Some of such strategies include the GLUE (Beven and Binley, 1992), and Uncertainty Estimation based on Local Error and Clustering (UNEEC) (Solomatine and Shrestha, 2009). The UNEEC method by considering the model residuals to be indicative of the model uncertainty quantifies the uncertainty in three steps including: clustering, model error probability distribution estimation, and building model uncertainty based on the error probability distribution (Solomatine and Shrestha, 2009). As a Bayesian approach, GLUE procedure uses parameters' sets randomized from the prior distribution to infer the output (posterior) distribution based on the simulations. Because the HBV version used in this study employs the GLUE technique, GLUE was also adopted for NAM and VHM. This was for the uniformity of calibration scheme to obtain an ensemble of simulated flow from each of the models.

Uncertainties from model input series due to observation errors, data limitation, in-filling of missing data values, etc lower the accuracy of model predictions. Another source of uncertainty is the incompatibility of the model structure with data availability. Because these uncertainties affect the flow-rainfall relationship, they exacerbate the parameter uncertainty during the calibration of the rainfall-runoff model. The GLUE technique adopted in this study as a framework for the calibration helps to quantify such uncertainties in the form of bounds on the final simulated flow. To implement the GLUE, so many e.g. 1000 sets of parameters were randomized based on the stipulated upper and lower limits of parameters. The model was run using each set of the parameters. The optimal set of parameters was taken as that which yielded the highest value of the 
objective function e.g. Nash-Sutcliffe Efficiency $\left(E_{\mathrm{NS}}\right)$ (Nash and Sutcliffe, 1970). However, for uncertainty quantification, all the sets of parameters and corresponding simulations which satisfied the objective function $\left(E_{\mathrm{NS}}>75 \%\right)$ were accepted. Normally, the uncertainty in the simulation can be given in terms of the maximum and minimum simulated flow ensemble. For brevity, the uncertainty in the form of $95 \%$ confidence interval was stipulated on the flow event corresponding to 10 -year return period. The 10-year return period was selected because of its relevance and the common use for planning, design and operation of water resource projects. Consider that $N_{\mathrm{ACC}}$ denotes the number of the sets of parameters for which objective function was satisfied. For the selected 10-year flow quantile, the simulated flow events from all the $N_{\mathrm{ACC}}$ sets of parameters were ranked from the highest to the lowest and the $\left[0.025 \times N_{\mathrm{ACC}}\right]^{\text {th }}$ and $\left[0.975 \times N_{\mathrm{ACC}}\right]^{\text {th }}$ values respectively comprised the upper and lower limits of the $95 \%$ confidence interval.

The model performance was evaluated both statistically and graphically. Statistically, the 'goodness-of-fit' was evaluated in terms of the $E_{\mathrm{NS}}$. The impact of anthropogenic factors, climate variability and/or change on hydrology seem to increasingly alter the frequency and severity of riskbased water disasters such as floods and drought conditions from their expected normal occurrences. For rainfall-runoff models to be applied for impact investigation, for instance due to climate variability and/or change on extreme flow events, the ability of the models to capture the high and low flow were deemed important for risk-based planning and management. Eventually, graphical plots of Box-Cox $(B C)$ transformed observed versus simulated series were made for the maximum as well as minimum flow in each year. The $B C$ (Box and Cox, 1964) transformation (Eq. 1) with the parameter $(\lambda)$ set to 0.25 was applied to give similar weights to the maximum and minimum flow events $(f)$ so as to obtain homoscedastic model residuals. Comparison of the simulated and observed cumulative flow was also made.

$$
B C(f)=\frac{f^{\lambda}-1}{\lambda}
$$

\subsection{Detection and attribution of changes in the flow}

According to Merz et al. (2012), the flow change attribution to assumed drivers can be done quantitatively in either data- or simulation-based way. Both ways were considered in this study.

\subsubsection{Data-based approach}

A data-based approach was implemented by comparing the correlation between the variation of flow with that of the rainfall series. The rainfall stations from Table 2 were used. For a particular station where flow data were from two sources, the series were converted to annual time scale and combined to form longer dataset than that obtained from each source. Finally, common data periods of flow and rainfall including 1940-1986, 1950-2000, 1965-2002 and 1912-1982, for Kagera, Kyoga, Blue Nile and Atbara respectively were used. High correlation between flow and rainfall was considered to indicate some evidence that the influence of the anthropogenic factors on the catchment runoff generation processes was limited.

\subsubsection{Simulation-based approach}

Because of the non-linearity of the rainfall-runoff relation, the data-based technique was complemented with a simulation-based approach. Three models were applied to study the covariation of observed flow and catchment rainfall-runoff considering a lumped catchment approach. In case of an unchanging catchment behavior, hence in case of insignificant anthropogenic factors, the temporal flow variation could be assumed to be fully described by the variation in the 
meteorological model inputs (rainfall and evapotranspiration) after keeping the model parameters constant over time. On the other hand, in case of a change in catchment behavior due to anthropogenic influence, there would be a temporal change in the difference between the observed and modeled runoff flow and sub-flow when model parameters are kept constant. Anthropogenic influences such as deforestation, overgrazing, significant expansion of urbanized areas, etc over a given catchment would: 1) affect the amount of infiltration into the soil, 2) alter the amount and velocity of the overland flow, 3) modify the rate and amount of evaporation, etc. Hence, these factors would alter the catchment response to the rainfall input. This difference in response should be visible through the changes in runoff volumes, sub-flow volumes, ratio between sub-flow volumes, model parameters describing the sub-flow response to such times such as the recession constant.

Because of the importance of studying the runoff sub-flow and more specifically the overland flow separately, a numerical digital filter was applied to split the flow into the various sub-components. This discharge splitting was done based on the sub-flow recession constants as applied in the tool provided by Willems (2009). The simulation-based approach to search for the temporal changes in the overland flow was analyzed in terms of variability using the Quantile Perturbation Method (QPM) (Ntegeka and Willems, 2008; Willems, 2013), and trend analyses based on Mann-Kendall (MK) (Mann, 1945; Kendall, 1975), and Cumulative Rank Difference (CRD) (Onyutha, 2016b, 2016c, 2016d) tests. The QPM was applied directly to the annual maxima, annual minima and annual mean flow. The MK and CRD tests were conducted on the model residuals.

\subsubsection{The quantile perturbation method of variability analysis}

The QPM uses the given series directly (i.e. without rescaling) to obtain quantile anomalies. This allows the QPM outputs to be importantly applicable, for instance, in revising design quantiles to account for the decadal or multi-decadal oscillations or variability in the hydro-meteorological variable. To apply the QPM, two series are derived from the same data set. One series (call it $v$ ) is the full series, and the other (denoted by $u$ ) is a sub-set extracted as a sub-period from the full series. The sub-series are contained in a moving window of a specified block length (taken as 15 years in this study). The moving window is first put at the beginning of the full time series and afterwards moved by 1 year at a time. For each moving window, quantile perturbation factors are computed as the quantiles above a selected exceedance probability threshold selected from $u$ and divided by their corresponding counterparts from $v$. The ultimate anomaly for the window under consideration is determined as the average of the perturbation factors for all empirical quantiles above a given threshold. The ultimate anomalies from the different moving window positions are considered to characterize the variability of the extreme quantiles in the series. An elaborate and systematic description of the QPM can be obtained from Ntegeka and Willems (2008) and Willems (2013).

\subsubsection{Analyses of trends in model residuals}

In the simulation-based procedure, with the premise that the models fully capture the catchment behavior, any deviation between observed and simulated flow can be attributed to internal disturbances which may include forest cover change, urbanization, river engineering, dam construction, etc (Harrigan et al., 2014). In this study, any persistent deviation between the observed and modeled flow was deemed to be reflected in the rejection of $H_{0}$ (no trend in model residuals). According to Onyutha (2016c), the uncertainty in trend analyses due to the influence from the selection of a particular method of change detection is not negligible for series with persistent fluctuations. Eventually, the $H_{0}$ (no trend in model residuals) were tested using two (i.e. MK and CRD) trend tests. 
The Mann-Kendall (MK) (Mann, 1945; Kendall, 1975) test

For the MK test, scores were assigned to the model residuals. The MK (Mann, 1945; Kendall, 1975) test statistic $S$ is defined as:

$$
S=\sum_{i=1}^{n-1} \sum_{j=i+1}^{n} \operatorname{sgn}\left(x_{j}-x_{i}\right)
$$

where $x_{j}$ and $x_{i}$ are the sequential data values in a sample of size $n$, and

$$
\operatorname{sgn}\left(x_{j}-x_{i}\right)=\left\{\begin{aligned}
1 & \text { if }\left(x_{j}-x_{i}\right)>0 \\
0 & \text { if }\left(x_{j}-x_{i}\right)=0 \\
-1 & \text { if }\left(x_{j}-x_{i}\right)<0
\end{aligned}\right.
$$

For $n \geq 8, S$ is approximately normally distributed with the mean $\mathrm{E}(S)=0$ and variance $V(S)$ given by (Mann, 1945; Kendall, 1975):

$$
V(S)=\frac{1}{18} n(n-1)(2 n+5)
$$

When tied data points exist, $V(S)$ becomes:

$$
V(S)=\frac{1}{18}\left(n(n-1)(2 n+5)-\sum_{k=1}^{h} g_{k}(k-1)(2 k+5)\right)
$$

where: $h$ is the number of tied groups, and $g_{\mathrm{k}}$ is the number of observations in the $k^{\text {th }}$ group. The standardized MK test statistic $Z_{\mathrm{MK}}$ which follows the standard normal distribution with mean (variance) of zero (one) is given by:

$$
Z_{M K}= \begin{cases}\frac{S-1}{\sqrt{V(S)}} & \text { for } S>0 \\ 0 & \text { for } S=0 \\ \frac{S+1}{\sqrt{V(S)}} & \text { for } S<0\end{cases}
$$

Positive and negative values of $S$ indicate increasing and decreasing trends respectively. The influence of auto-correlation on the variance of $S$ can be corrected based on the procedure suggested by Yue and Wang (2004). The null hypothesis $H_{0}$ (no trend in residuals) is accepted if $\left|Z_{\mathrm{MK}}\right|$ is less than the standard normal variate $Z_{\alpha / 2}$ where $\alpha \%$ is the significance level; otherwise the alternative hypothesis $H_{1}$ (there is trend in residuals) can be accepted. 
Cumulative Rank Difference (CRD) (Onyutha, 2016b; 2016c; 2016d) test

To conduct the recently introduced CRD test on the model residuals, freely available trend and variability analyses tool referred to as CRD-NAIM (Onyutha, 2016b; 2016c; 2016d) downloaded from https://sites.google.com/site/conyutha/tools-to-download/ [accessed 15-12-2016] was used.

If for the given series $X$, another dataset $Y$ is obtained as the replica of $X$, the rescaled series $d$ in terms of the exceedance and nonexceedance counts of data points can be obtained by (Onyutha, $2016 b ; 2016 c)$ :

$d_{i}=2 \sum_{j=1}^{n} \operatorname{sgn}_{1}\left(y_{j}-x_{i}\right)-\left(n-\sum_{j=1}^{n} \operatorname{sgn}_{2}\left(y_{j}-x_{i}\right)\right)$ for $i=1,2, \ldots, n$

where,

$$
\begin{aligned}
& \operatorname{sgn}_{1}\left(y_{j}-x_{i}\right)= \begin{cases}1 & \text { if }\left(y_{j}-x_{i}\right)>0 \\
0 & \text { if }\left(y_{j}-x_{i}\right) \leq 0\end{cases} \\
& \operatorname{sgn}_{2}\left(y_{j}-x_{i}\right)= \begin{cases}1 & \text { if }\left(y_{j}-x_{i}\right)=0 \\
0 & \text { if }\left(y_{j}-x_{i}\right)<0 \text { or }\left(y_{j}-x_{i}\right)>0\end{cases}
\end{aligned}
$$

The CRD trend statistic $T$ is computed using (Onyutha, 2016b):

$$
T=\frac{6}{\left(n^{3}-n\right)} \sum_{i=1}^{n-1} \sum_{j=1}^{i} d_{j}
$$

An upward/downward monotonic trend is indicated by a positive/negative value of $T$. The distribution of $T$ is approximately normal with the mean of zero and variance $\left(V_{1}\right)$ given by (Onyutha, 2016c, 2016d):

$$
V_{1}=\frac{1}{n-1}\left(1-\frac{10}{17} c^{2}-\frac{7}{17} c\right)
$$

where $c$ (Eq. 12) is the measure of ties in the data (Onyutha, 2016d) such that

$$
c=\frac{-1}{n^{2}-n}\left(n-\sum_{i=1}^{n} \sum_{j=1}^{n} \operatorname{sgn}_{2}\left(y_{j}-x_{i}\right)\right)
$$

and $\operatorname{sgn}_{2}\left(y_{j}-x_{i}\right)$ is as defined in Eq. (9).

The standardized statistic of the CRD test $Z_{C R D}$ which follows the standard normal distribution with mean (variance) of zero (one) is given by Eq. (13). At the significance level $\alpha \%$, the null hypothesis $H_{0}$ (no trend) is accepted if the $p$-value (probability value, $p$ ) based on $|Z|$ is greater than the nominal $\alpha$. The term $V_{2}$ of Eq. (13) takes into account the correction of $V_{1}$ from the influence of 
autocorrelation (Onyutha, 2016d) or long-term persistence in terms of the Hurst exponent $H$ (Onyutha, 2016c). For brevity, $V_{1}$ was computed in terms of $H$ such that,

$$
Z_{C R D}=\frac{T}{\sqrt{V_{2}}}
$$

where

$$
V_{2}= \begin{cases}V_{1} & \text { if } H \leq 0.5 \\ V_{1} \times b n^{a} & \text { if } H>0.5\end{cases}
$$

such that $b=1.55490-1.20344 H-0.27340 H^{2}, a=-0.62304+0.87827 H+0.82220 H^{2}$, and as implemented in the CRD-NAIM tool $H$ can be computed using the given series in terms of the autocorrelation function for fractional Gaussian noise model (see e.g. Mandelbrot, 1965). Alternatively, $H$ can be approximated in terms of the generalized Hurst exponent $H(q \#)$ based on the scaling of renormalized $q \#-$ moments of the distribution (see e.g. Di Matteo, 2007).

\section{$4 \quad$ Results and discussion}

\subsection{Co-variation of flow and rainfall}

Figure 2 shows the temporal variation of the mean annual flow at the catchment outlet and the catchment-averaged rainfall for common data periods as described in Section 3.3.1. The closeness between the flow and rainfall variation is visibly evident. Further still, the null hypothesis $H_{0}$ (no correlation between rainfall and flow) at the significance level of 5\% was rejected for all the selected catchments, i.e. Kagera and Kyoga, Blue Nile and Atbara (Figure 2 a-d).
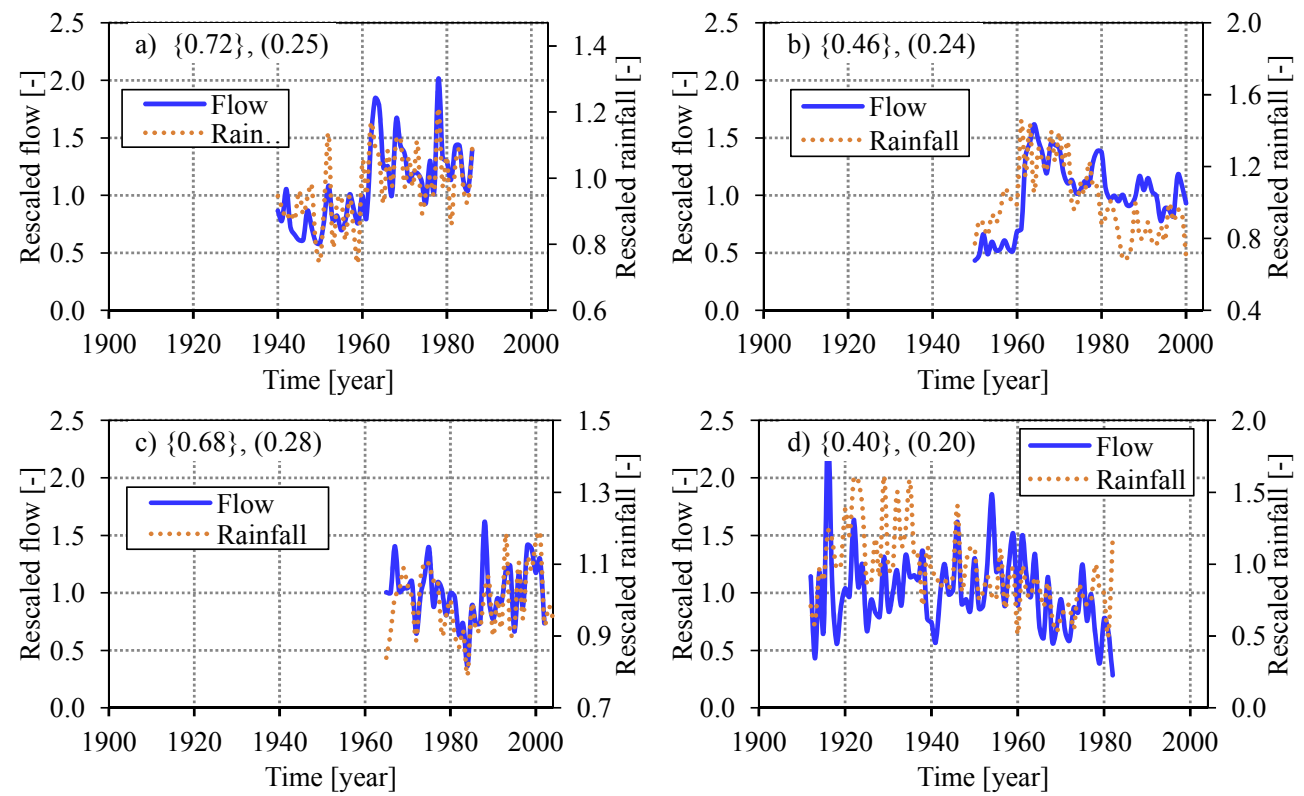

Figure 2 Variation in the mean annual flow and catchment-wide rainfall in a) Kagera, b) Kyoga, c) Blue Nile, and d) Atbara. The label in " \{\} " shows the correlation between the rainfall and flow; and "( )" comprises the correlation critical value at the significance level of $5 \%$. 
Table 3 shows the correlation between the variation of mean seasonal and mean annual flow at the catchment outlet and the rainfall from individual stations upstream of the outlet. Although there was some insignificant anti-correlation especially in the MAM (JJAS) season for Blue Nile and Atbara (Kagera and Kyoga), generally the correlation for the annual time scale was significantly positive for all the selected catchments. This realization was also obtained for the seasons from which the variation in the annual rainfall emanates, i.e. OND (for Kagera and Kyoga) and JJAS (for Blue Nile and Atbara). Conclusively, the variation in seasonal and annual flow over the selected data period was mainly due to the variability in rainfall.

Table 3 Correlation between the variation of rainfall and river flow

\begin{tabular}{|c|c|c|c|c|c|c|c|c|c|}
\hline Rainfall & MAM & JJAS & ONDJF & Annual & Rainfall & MAM & JJAS & OND & Annual \\
\hline \multicolumn{5}{|c|}{ Blue Nile $\{0.28\}$} & \multicolumn{5}{|c|}{ Kyoga $\{0.24\}$} \\
\hline Blul & -0.04 & 0.29 & 0.62 & 0.34 & Kyol & 0.28 & -0.12 & 0.27 & 0.32 \\
\hline Blu2 & -0.11 & 0.34 & 0.57 & 0.32 & Kуо2 & 0.25 & 0.04 & 0.26 & 0.41 \\
\hline Blu3 & -0.21 & 0.47 & 0.53 & 0.50 & Kyo3 & 0.23 & 0.13 & 0.36 & 0.36 \\
\hline Blu4 & 0.10 & 0.46 & 0.09 & 0.31 & Kyo4 & 0.21 & 0.12 & 0.36 & 0.40 \\
\hline Blu5 & -0.15 & 0.69 & 0.26 & 0.55 & CW & 0.32 & 0.06 & 0.38 & 0.46 \\
\hline $\mathrm{CW}$ & -0.12 & 0.69 & 0.59 & 0.68 & \multicolumn{5}{|c|}{ Kagera $\{0.28\}$} \\
\hline \multicolumn{5}{|c|}{ Atbara } & Kag1 & 0.38 & 0.12 & 0.36 & 0.64 \\
\hline Abt1 & -0.06 & 0.37 & -0.06 & 0.36 & Kag2 & 0.11 & 0.24 & 0.52 & 0.54 \\
\hline Abt2 & -0.16 & 0.44 & 0.06 & 0.44 & Kag3 & 0.06 & -0.14 & 0.34 & 0.29 \\
\hline Abt3 & -0.09 & 0.59 & -0.08 & 0.58 & Kag4 & 0.37 & 0.21 & 0.39 & 0.53 \\
\hline Abt4 & -0.24 & 0.57 & 0.01 & 0.61 & $\mathrm{CW}$ & 0.34 & 0.18 & 0.60 & 0.72 \\
\hline $\mathrm{Abt5}$ & -0.02 & 0.36 & 0.11 & 0.35 & \multirow{4}{*}{\multicolumn{5}{|c|}{$\begin{array}{l}\text { For bold values } H_{0} \text { (no correlation) was } \\
\text { rejected at the significance level of } 5 \% \text {. } \\
\quad \text { CW stands for Catchment-Wide. } \\
\text { ical value at the significance level of } 5 \% \text {. } \\
\text { ere } 0.22(\mathrm{Abt} 1), 0.37 \text { (Abt2), } 0.35 \text { (Abt3), } \\
0.22(\mathrm{CW}) \text {. }\end{array}$}} \\
\hline Abt6 & 0.12 & 0.42 & -0.03 & 0.38 & & & & & \\
\hline $\mathrm{CW}$ & -0.04 & 0.42 & 0.05 & 0.40 & & & & & \\
\hline cor & 0.0 & 1otes $\mathrm{t}$ & correla & $\begin{array}{l}\text { on critic } \\
\text { hent wer } \\
\text {, and } 0\end{array}$ & & & & & \\
\hline
\end{tabular}

\subsection{Rainfall-runoff modeling}

Figure 3 shows the time series of the observed and simulated Blue Nile and Kagera flow. The model parameters considered for calibration using the GLUE technique can be found listed in Appendix Table A1. Though for brevity the uncertainty bounds based on GLUE for the entire calibration period were not included in Figure 3, the difference between the upper and lower limits of the $95 \%$ confidence interval on the simulated 10-year flow event as a percentage of the 10 -year empirical flow quantile for HBV, NAM and VHM was respectively 35.8, 29.2, 40.3\% for Blue Nile, and 41.2, 51.8, 46.2\% for Kagera. Generally, the predictive uncertainties were higher for Kagera than those of the Blue Nile. Furthermore, this observation is supported by the visual judgment considering each model in which again better modeled results were obtained for the Blue Nile (Figure 3 a-b) than for the Kagera (Figure 3 c-d) catchment. This realization was because of the larger catchment size and stronger seasonal differences for the Blue Nile which led to smoother catchment response to rainfall than that for the Kagera catchment. 

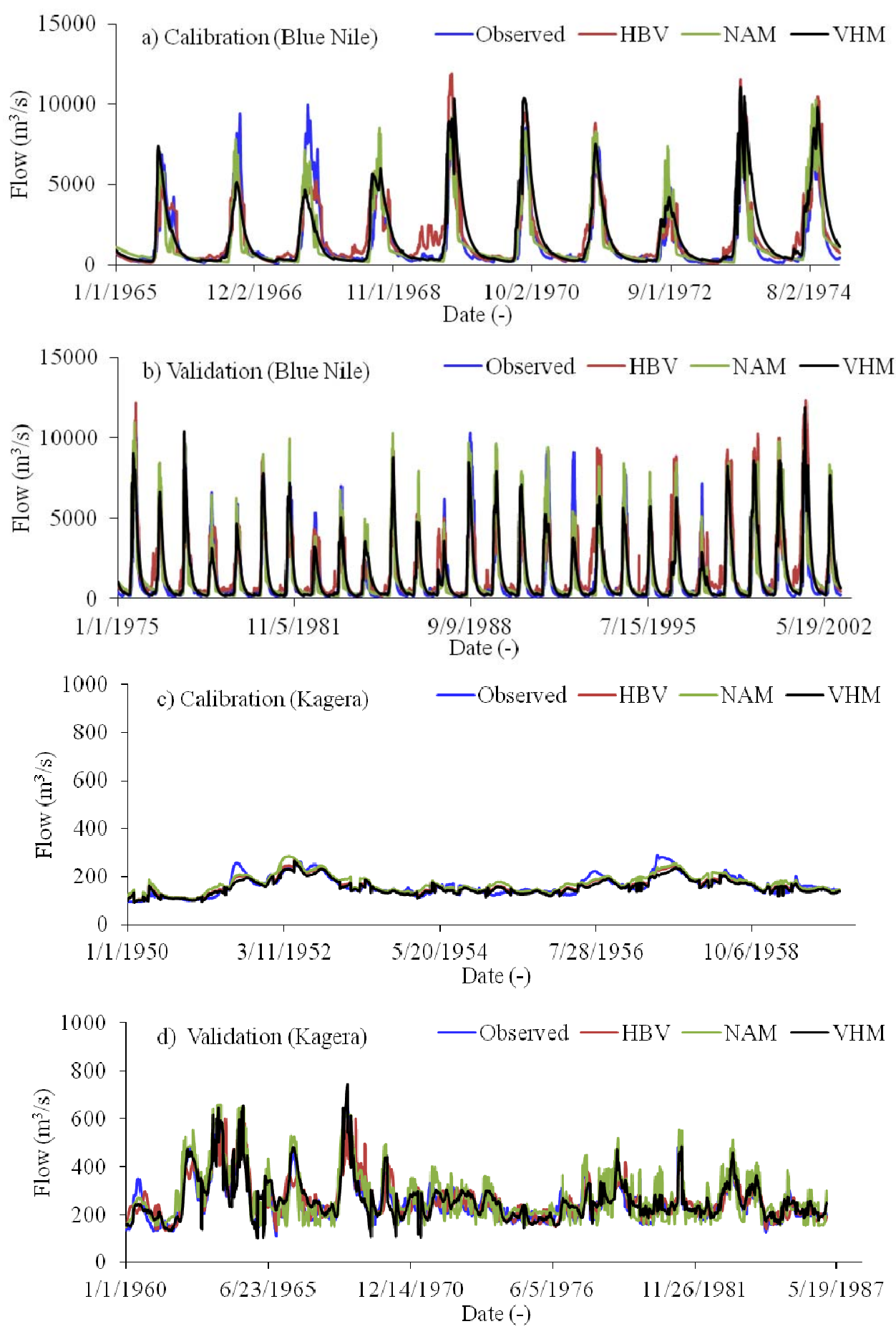

Figure 3 Simulated $v s$. observed daily flow for a)-b) Blue Nile, and c)-d) Kagera catchments

Table 4 shows the statistical assessment of the models' performance. The values of the $E_{\mathrm{NS}}$ for calibration were acceptably high. Consistent with the visual judgment from Figure $\mathbf{3} \mathbf{b}$ and $\mathbf{d}$, the model performance (though reasonably good) in the validation was better for the Blue Nile than that of the Kagera catchment. In reference to the model calibration results, the validation $E_{\mathrm{NS}}$ for VHM, HBV, and NAM exhibited a drop of 8, 10 and $8 \%$ (for the Blue Nile) and 13, 14 and 12\% (for Kagera) respectively. In order to check whether this drop in the $E_{\mathrm{NS}}$ for Kagera could be explained by model over-calibration, the validation input series were considered as independent model inputs. When calibration based on the GLUE scheme was repeated for this new input, there was no 
significant increase in the $E_{\mathrm{NS}}$ values compared to those for the validation shown in Table 4. One reason for the $E_{\mathrm{NS}}$ drop could be the lower data quality taking into account that some measurement stations tend to be irregularly operational due to poor maintenance. Another potential reason could be the difficulty in the models to capture the dynamics of runoff generation at the catchment level especially due to the recovery of the equatorial region from the step jump in the flow mean which occurred at the beginning of the validation period for Kagera (i.e. 1960-1986). Because the $E_{\mathrm{NS}}$ values for all the models were higher than 0.6 for all the validation runs, the modeled flow was deemed adequate for the empirical investigation of the possible change in catchment rainfall-runoff response.

Table 4 Statistical measures of the agreement between the observed and simulated daily flow for the Blue Nile and Kagera catchments

\begin{tabular}{lcc}
\hline & Blue Nile & Kagera \\
\hline \multicolumn{3}{c}{ Calibration } \\
\hline Period & $1965-1974$ & $1950-1959$ \\
VHM & 0.76 & 0.74 \\
HBV & 0.77 & 0.73 \\
NAM & 0.78 & 0.70 \\
\hline \multicolumn{3}{c}{ Validation } \\
\hline Period & $1975-2002$ & $1960-1986$ \\
VHM & 0.70 & 0.65 \\
HBV & 0.69 & 0.63 \\
NAM & 0.71 & 0.62 \\
\hline
\end{tabular}

Figure 4 shows the graphical assessment of the 'goodness-of-fit' between the Box-Cox transformed observed and modeled daily maximum and minimum flow in a year. Good model performance was obtained for both the annual maximum (Figure 4d) and minimum (Figure 4e) flow of Kagera catchment. For the Blue Nile, though the performances of all the models were good for the annual maxima (Figure 4a), the HBV model tended to over-estimate most of the annual minima (Figure 4b). With respect to the cumulative flow volumes (Figure 4c and $\mathbf{f}$ ), the models gave slight overestimations. For Kagera catchment, the slight over-estimations might have been due to the lower performance of the simulation results from the validation period. Note that because the Blue Nile flow has stronger seasonal variation, the flow scatter was more wide-spread for the Blue Nile (Figure 4a-b) than for the Kagera (Figure 4c-d). Based on these performance evaluation results, it was generally concluded that the three models were jointly suitable for making an assessment of potential temporal changes in the catchment rainfall-runoff responses. 

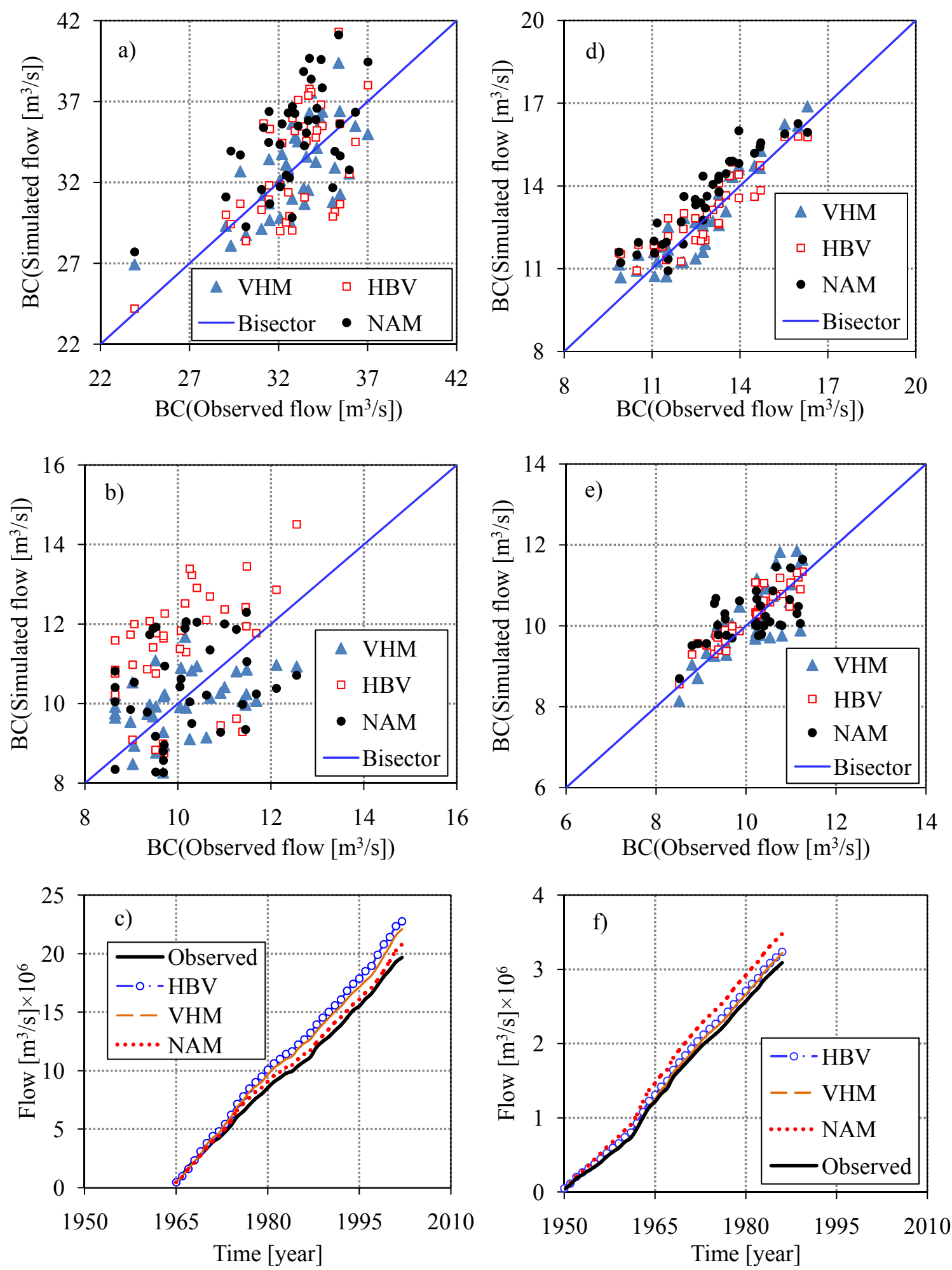

Figure 4 Evaluation of the model performance considering Box-Cox $(B C)$ transformed $(\mathrm{a}, \mathrm{d})$ maximum flow in a year, $(b, e)$ minimum flow in a year. Charts (c, f) are for cumulative flow, (a)(c) Blue Nile catchment and (d)-(f) Kagera catchment. 


\subsection{Changes in observed and simulated overland flow}

Figure 5 shows changes in observed and simulated daily maximum and minimum overland flow in each year in terms of the QPM quantile anomalies for moving block lengths of 15 years. To interpret the results in Figure 5, an anomaly of, say, 5\% for a given year indicated that the extreme quantiles in the sub-period centered on this year were on average $5 \%$ higher than the quantiles obtained based on the full time series (taken as the reference i.e. anomaly of zero). For the annual maximum and mean overland flow at the Blue Nile (Figure 5a, c), there were oscillation highs (OHs) in the mid 1960s to late 1970s, and in the 1990s. There was an oscillation low (OL) from the late 1970s to around 1990. Taye and Willems (2013) found similar results especially for the annual maximum flow in the upper Blue Nile catchment. However, for the annual minimum flow (Figure 5b), the period from the mid 1960s to late 1970s (early 1980s to late 1990s) was characterized by an OH (OL). For Kagera, the period 1950-1959 (1960-1986) was characterized by an OL (OH) (Figure 5d-f). Some slight over- or under-estimation of the observed changes was demonstrated in the QPM anomalies. 

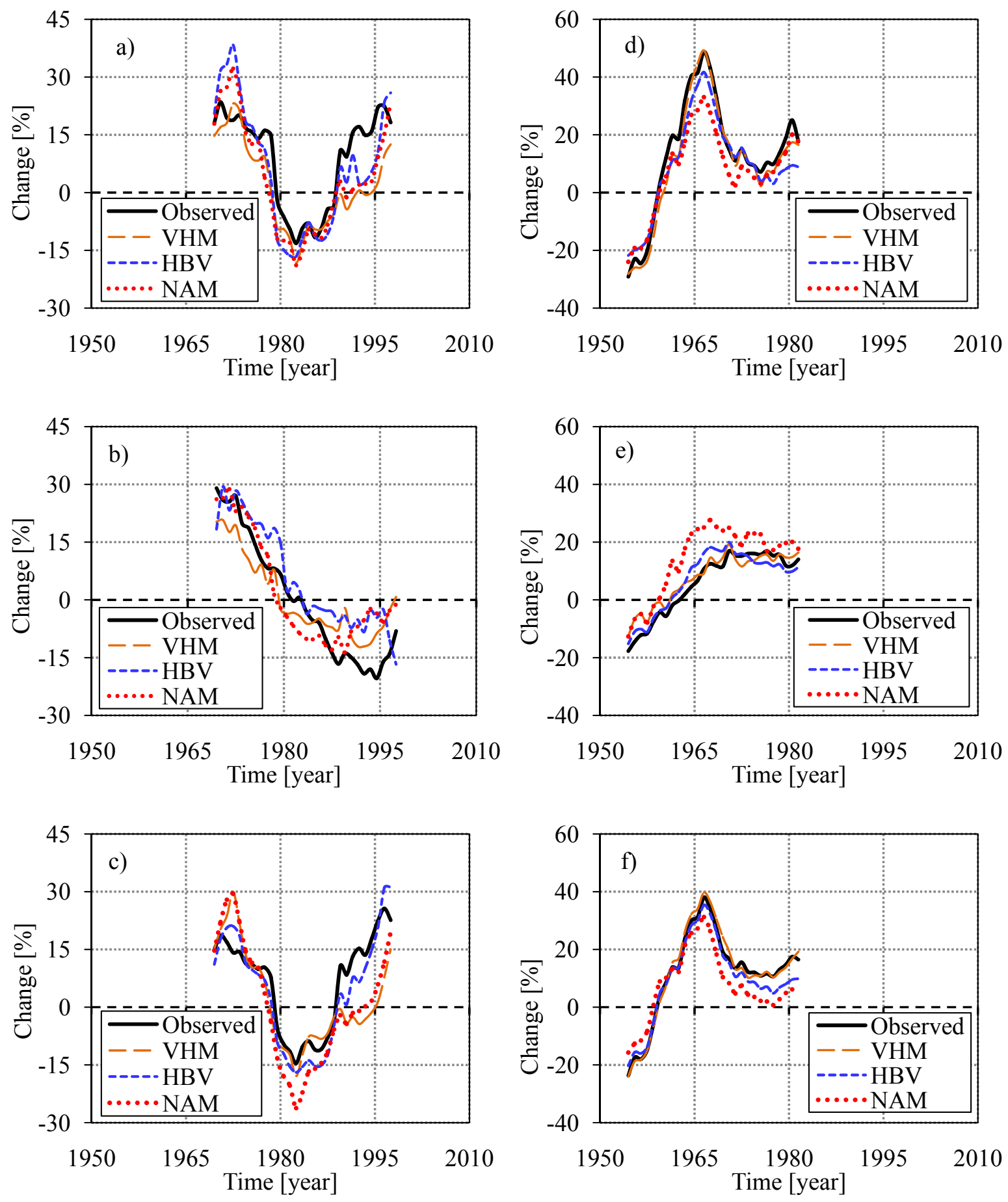

Figure 5 QPM results for observed and modeled overland flow in terms of anomalies in the a) annual maxima, b) annual minima and c) annual mean. The charts (a)-(c) and (e)-(f) are for Blue Nile and Kagera catchments respectively.

Table 5 shows the probability values of the trend tests conducted on model residuals computed based on the annual maxima, annual minima and annual mean flow. For the Blue Nile catchment, the $p$-values were greater than the nominal significance level of 0.05 for all the models. This showed that the magnitude of the model residuals did not depend on the time of observations. In other words, the evidence to reject the $H_{0}$ (no trend in residuals) was statistically insufficient at the significance level of $5 \%$. However for Kagera, $H_{0}$ was rejected based on the MK test at the level at 
$5 \%$ level for the residual of HBV computed using annual minimum flow. Although this might suggest some possible change in catchment behavior, it was not deemed conclusive since $H_{0}$ was accepted based on the results from the two other models i.e. NAM and VHM. Moreover for the CRD test, $H_{0}$ was accepted for the same HBV residuals. Generally, the $p$-values based on the residual from the annual minima flow were lower than those from the annual mean or maxima. Of course, this was not surprising because the structures of most hydrological models are traditionally designed to capture rather the flooding events than low flow conditions (Staudinger et al. 2011). Furthermore, the use of the overall water-balance-based objective function (as adopted in this study) for model calibration or evaluation favors the performance of the hydrological models more for high flow than low flow (Onyutha 2016a). Though not shown in Table 5, the residual trend directions in terms of their signs were found different among the models in some cases. This could have been because of the difference between the models in terms of their structures and sets of calibration parameters used to capture the runoff generation dynamics.

Table 5 The $p$-values of MK and CRD trend tests conducted on the model residuals

\begin{tabular}{ccccccc}
\hline \multirow{2}{*}{ Residual based on : } & \multirow{2}{*}{ Model } & \multicolumn{2}{c|}{ Blue Nile } & \multicolumn{2}{c}{ Kagera } \\
\cline { 3 - 6 } & & MK test & CRD test & MK test & CRD test \\
\hline \multirow{3}{*}{ Annual mean } & HBV & 0.741 & 0.593 & 0.628 & 0.717 \\
& NAM & 0.851 & 0.845 & 0.890 & 0.503 \\
& VHM & 0.735 & 0.821 & 0.700 & 0.854 \\
\hline \multirow{4}{*}{ Annual maxima } & HBV & 0.991 & 0.841 & 0.927 & 0.779 \\
& NAM & 0.371 & 0.418 & 0.238 & 0.164 \\
& VHM & 0.867 & 0.853 & 0.953 & 0.876 \\
\hline \multirow{3}{*}{ Annual minima } & HBV & 0.404 & 0.513 & $\mathbf{0 . 0 3 9}$ & 0.062 \\
& NAM & 0.428 & 0.402 & 0.114 & 0.211 \\
& VHM & 0.257 & 0.325 & 0.208 & 0.301 \\
\hline
\end{tabular}

For bold value, $H_{0}$ (no trend) was rejected at the significance level of $5 \%$

It is worth mentioning that some minor discrepancies between the observed and modeled flow were demonstrated in the QPM results. These discrepancies could be indicative of some possible slight changes in the catchment behavior, which may be attributed to an anthropogenic influence. A number of previous studies also ascribed hydrological changes in the different parts of the Nile basin to anthropogenic factors including: human influence on the Lake Tana in terms of abstractions from the influent rivers (Legesse et al., 2004), an increase in cultivation area in the Chemoga catchment (Bewket and Sterk, 2005), deforestation for agriculture in the Gilgel Abay catchment (Rientjes et al., 2011), increase in the population and intensification of agriculture in Sudan (Elmqvist, 2005), conversion of forests to farming land in the Mara catchment (Mango et al., 2011), etc.

Unlike in some other studies, the significant catchment changes and their effects on catchment runoff flow were not confirmed in this study. Despite the slight over- or under-estimation of the observed changes for both selected catchments, the outputs from all the models indeed exhibited close agreement in capturing the flow variability or quantile changes (by the QPM) (Figure 5). Moreover, the $H_{0}$ (no trends in the model residuals) was generally accepted at the significance level of 5\% level based on both the MK and CRD test. These results from the QPM for variability, and MK and CRD tests for trend analyses generally indicated that the changes in the catchment behavior in transforming the rainfall input into runoff were minimal over the data period considered in this study. In related studies, similar conclusions were made by e.g. Taye and Willems (2013) 
and Gebrehiwot et al. (2013), all done for the period 1960-2004. According to Gebrehiwot et al. (2013), the integrated functioning of the catchments including Birr, Upper-Didesa, Gilgel Abbay, and Koga sub-catchments of the Blue Nile as a main source of the River Nile showed minimal changes. Taye and Willems (2013) also concluded that there were no discernible changes noted for the Blue Nile catchment response. Therefore as shown in this study, the temporal flow variation in the catchments selected from the two main sources of the River Nile may be primarily attributed to the rainfall variation.

According to Harrigan et al. (2014), despite the statistical detection of trends, rigorous attribution is required in decision making on long-term management and adaptation strategies. In the same line, the call for increased rigor in attribution through consistency, inconsistency and provision of confidence statement was made by Merz et al. (2012). Furthermore, Harrigan et al. (2014) suggested the method of Multiple Working Hypothesis (MMWHs) as a systematic examination of known drivers to explain the full signal of change. In line with the MMWHs, some of the working hypotheses (which were not investigated in this study) but deemed to potentially influence the catchment behavior (though insignificantly) across the study area and should be considered for further research in a combined way include: urbanization, forest cover transition, water abstractions or diversions, agricultural land-use and management change, etc. Another factor which could not be ruled out in influencing the change detection was the questionable quality of hydro-meteorological data in the study area. Once the large data requirement for attribution become manageable in the future, an interesting attempt would be to expose the synergistic interaction (if any) of the drivers of the flow changes in the various catchments of the Nile basin.

Some of the possible limitations in applying the methodology used in this study are as follow:

a) It may be possible that the mismatch between the observed and modeled flow used to give insight about the change in catchment behavior can be due to the questionable data quality. Some of the possible data-related uncertainties could be the observation errors, in-filling of missing values, errors in derivation of the hydro-climatic variables e.g. rainfall, etc.

b) In case the changes in the catchment behavior are caused by several factors e.g. the influence of anthropogenic factors combined with the impacts of climate variability on hydrological processes, the methodology used in this study cannot be able to separate the various layers of the synergistic influences in a systematic way for flow change attribution.

\section{$5 \quad$ Conclusions}

This paper assessed the main attribute of the mean and extreme flow variation in four catchments selected based on the two main sources of the River Nile including the White Nile and Blue Nile in the Equatorial region of the study area and the Ethiopian Highlands respectively. The selected catchments were those of Lake Kyoga and River Kagera (from the Equatorial region), as well as Blue Nile and River Atbara (in Sudan and Ethiopia). In order to investigate whether this flow variation could be attributable to that of rainfall, the co-variation of the rainfall and flow was assessed at catchment scale. To investigate if there was any possible change in catchment behavior to interfere with the flow-rainfall relationship, three rainfall-runoff models including NAM, VHM and HBV were used to simulate daily runoff using data (falling within the period 1948-2003) from the major catchment of each River Nile source-based region i.e. Kagera and Blue Nile. The rainfallrunoff modeling was done under the assumption of unchanging catchment characteristics over longterm data periods. The idea here was that the change in catchment behavior due to an anthropogenic influence would lead to persistent difference in the observed and modeled flow and sub-flow such as the overland sub-flow. The investigation of this deviation was made in terms of: changes in anomalies based on the quantile perturbation method, and detection of trends in the residuals using the Mann-Kendall and cumulative rank difference tests. 
The key conclusions from this study were as follow:

- For all the selected catchments, the null hypothesis $H_{0}$ (no correlation between rainfall and flow) was generally rejected at the significance level $\alpha$ of $5 \%$ in both seasonal and annual time scales. This suggested that the variation in the flow of the River Nile basin over the selected data period was strongly attributable to that in rainfall.

- Regardless of the change detection method or rainfall-runoff model used, close agreement between the changes in observed and simulated flow was generally obtained in both selected catchments. For instance, the evidence to reject the $H_{0}$ (no trend in the residuals) based on both the Mann-Kendall and cumulative rank difference tests was generally statistically insufficient at $\alpha=5 \%$ for all the models and selected catchments. These results suggested that the impacts of the changes in catchment behavior on the hydrology of the given catchments were nominal. This implied that the changes in catchment characteristics of the Nile basin did not significantly influence the attribution of the variation in flow to that of rainfall (especially over the selected data period).

- Given that the main attribute of the observed flow variation was that in rainfall, indeed an insight into the prediction of flow variation can be obtained from the rainfall variability drivers e.g. those provided recently for the entire Nile basin by Onyutha and Willems (2015b). In line with this, for instance, Siam and Eltahir (2015) found it possible to obtain some logical predictive estimates of annual flow for the northern half of the River Nile based on the teleconnection between the Indian Ocean and the Nile basin. However, to reflect the difference in micro-climate (micro-scale features) of the study area, it is recommended that more studies be carried on many other catchments covering the entire Nile basin.

\section{Acknowledgement}

The research was financially supported by an IRO Ph.D. scholarship of KU Leuven.

\section{References}

Abtew W, Melesse AM, Dessalegne T (2009) El Niño Southern Oscillation link to the Blue Nile River basin hydrology. Hydrol Process 23:3653-3660

AghaKouchak A, Habib E (2010) Application of a conceptual hydrologic Model in teaching hydrologic processes. Int J Engng Ed 26(4):963-973

AghaKouchak A, Nakhjiri N, Habib E (2013) An educational model for ensemble streamflow simulation and uncertainty analysis. Hydrol Earth Syst Sci 17:445-452

Allen RG, Pereira LS, Raes D, Smith M (1998) Crop evapotranspiration - guidelines for computing crop water requirements - FAO Irrigation and Drainage Paper 56, ISBN 92-5-104219-5. FAO Food and Agriculture Organization of the United Nations, Rome, Italy.

Bergström S (1976) Development and application of a conceptual runoff model for Scandinavian catchments, SMHI RHO 7, Norrköping, Sweden.

Beven KJ, Binley AM (1992) The future role of distributed models: model calibration and predictive uncertainty. Hydrol Process 6:279-298

Bewket W, Sterk G (2005) Dynamics in land cover and its effect on stream flow in the Chemoga watershed, Blue Nile basin, Ethiopia. Hydrol Process 19:445-458

Box, GEP, Cox DR (1964) An analysis of transformations. J Roy Statist Soc 26:211-243 
Camberlin P (1997) Rainfall anomalies in the source region of the Nile and their connection with the Indian summer monsoon. J Clim 10:1380-1392

Camberlin P (2009) Nile Basin Climates. In: Dumont HJ (ed) The Nile: origin, environments, limnology and human use, monographiae biologicae, vol. 89, Springer, Dordrecht, pp 307-333

DHI (2007) MIKE11 - A modeling system for rivers and channels. Reference manual, DHI water \& environment, Hørsholm, Denmark, pp. 278-325

Di Matteo T (2007) Multi-scaling in finance. Quant Finance 7(1):21-36

Elmqvist B (2005) Land use assessment in the drylands of Sudan using historical and recent high resolution satellite data. The $31^{\text {st }}$ International Symposium on Remote Sensing of the Environment, Jun 2004; St. Petersburg, ISRSE, 2005.

FAO (1997) Irrigation potential in Africa: a basin approach, M-54, FAO Land and Water Bull., Rome Italy.

Gebrehiwot SG, Seibert J, Gärdenäs AI, Mellander PE, Bishop K (2013) Hydrological change detection using modeling: Half a century of runoff from four rivers in the Blue Nile Basin. Water Resour Res 49:3842-3851

Harrigan S, Murphy C, Hall J, Wilby RL, Sweeney J (2014) Attribution of detected changes in streamflow using multiple working hypotheses. Hydrol Earth Syst Sci 18:1935-1952

Hoell A, et al. (2015) The forcing of monthly precipitation variability over Southwest Asia during the Boreal Cold Season. J Clim 28(18):7038-7056

Kalnay, E. et al. (1996). The NCEP/NCAR 40-year reanalysis project. Bull Am Meteorol Soc 77(3):437-471

Kendall MG (1975) Rank correlation methods, fourth ed. Charles Griffin, London.

Kennedy \& Donkin Power Ltd in Association with Sir Alexander Gibb \& Partners and Kananura Melvin Consulting Engineers (1997): Hydropower Development Plan Part 1 (Final Report) Volume 8, and Environmental Impact Assessment (Stage 1)-Volume 8, Uganda Electricity Board, Kampala, Uganda.

Legesse D, Vallet-Coulomba C, Gasse F (2003) Hydrological response of a catchment to climate and land use changes in Tropical Africa: case study South Central Ethiopia. J Hydrol 275:67-85

Legesse D, Vallet-Coulomb C, Gasse F (2004) Analysis of the hydrological response of a tropical terminal lake, Lake Abiyata (Main Ethiopian Rift Valley) to changes in climate and human activities. Hydrol Process 18:487-504

Madsen H (2000) Automatic calibration of a conceptual rainfall-runoff model using multiple objectives. J Hydrol 235:276-288

Mandelbrot B (1965) Une classe de processus stochastiques homothetiques a soi: Application a la loi climatologique de H.E. Hurst. Compt Rend Acad Sci 260:3274-3276

Mango LM, Melesse AM., McClain ME, Gann D, Setegn SG (2011) Land use and climate change impacts on the hydrology of the upper Mara River Basin, Kenya: results of a modeling study to support better resource management. Hydrol Earth Syst Sci 15:2245-2258.

Mann HB (1945) Nonparametric tests against trend. Econometrica 13(3):245-259.

Merz B, Vorogushyn S, Uhlemann S, Delgado J, Hundecha Y (2012) HESS Opinions "More efforts and scientific rigour are needed to attribute trends in flood time series". Hydrol Earth Syst Sci 16:1379-1387 
Nash JE, Sutcliffe JV (1970) River flow forecasting through conceptual models part I-a discussion of principles. J Hydrol 10:282-290

Nicholson SE (1996) A review of climate dynamics and climate variability in Eastern Africa, in: The Limnology, Climatology and Paleoclimatology of the East African Lakes, edited by: Johnson TC and Odada EO, Gordon and Breach, Amsterdam, the Netherlands, pp. 25-56.

Ntegeka V, Willems P (2008) Trends and multidecadal oscillations in rainfall extremes, based on a more than 100 year time series of 10min rainfall intensities at Uccle, Belgium. Water Resour Res 44:W07402. doi:10.1029/2007WR006471

Olang LO, Fürst J (2011) Effects of land cover change on flood peak discharges and runoff volumes: model estimates for the Nyando River Basin, Kenya. Hydrol Process 25:80-89

Onyutha C (2016a) Influence of hydrological model selection on simulation of moderate and extreme flow events: A case study of the Blue Nile basin. Adv Meteorol 2016(Article ID 7148326):1-28, doi:10.1155/2016/7148326

Onyutha C (2016b) Identification of sub-trends from hydro-meteorological series. Stoch Env Res Risk Assess 30:189-205

Onyutha C (2016c) Statistical uncertainty in hydrometeorological trend analyses. Adv Meteorol 2016(Article ID 8701617):1-26, doi: 10.1155/2016/8701617

Onyutha C (2016d) Statistical analyses of potential evapotranspiration changes over the period 1930-2012 in the Nile River riparian countries. Agric For Meteorol 226-227:80-95

Onyutha C, Willems P (2015a) Empirical statistical characterization and regionalization of amplitude-duration-frequency curves for extreme peak flows in the Lake Victoria Basin, East Africa. Hydrol Sci J 60(6):997-1012

Onyutha C, Willems P (2015b) Spatial and temporal variability of rainfall in the Nile Basin. Hydrol Earth Syst Sci 19:2227-2246

Onyutha C, Willems P (2015c) Uncertainty in calibrating generalised Pareto distribution to rainfall extremes in Lake Victoria Basin. Hydrol Res 46(3):356-376

Rientjes THM, Haile AT, Kebede E, Mannaerts CMM, Habib E, Steenhuis TS (2011) Changes in land cover, rainfall and stream flow in Upper Gilgel Abbay catchment, Blue Nile basin Ethiopia. Hydrol Earth Syst Sci 15:1979-1989

Sheffield J, Goteti, G, Wood EF (2006) Development of a 50-year high-resolution global dataset of meteorological forcings for land surface modeling. J Clim 19(13):3088-3111

Siam MS, Eltahir EAB (2015) Explaining and forecasting interannual variability in the flow of the Nile River. Hydrol Earth Syst Sci 19:1181-1192

Solomatine DP, Shrestha DL (2009) A novel method to estimate model uncertainty using machine learning techniques. Water Resour Res 45:W00B11, doi:10.1029/2008WR006839

Staudinger M, Stahl K, Seibert J, Clark MP, Tallaksen LM (2011) Comparison of hydrological model structures based on recession and low flow simulations. Hydrol Earth Syst Sci 15:34473459

Taye MT, Willems P (2013) Identifying sources of temporal variability in hydrological extremes of the upper Blue Nile basin. J Hydrol 499:61-70

Tierney JE, Smerdon JE, Anchukaitis KJ, Seager R (2013) Multidecadal variability in East African hydroclimate controlled by the Indian Ocean. Nature 493:389-392

Willems P (2009) A time series tool to support the multi-criteria performance evaluation of rainfallrunoff models. Environ Model Softw 24:311-321 
Willems P (2013) Multidecadal oscillatory behaviour of rainfall extremes in Europe. Clim Chang 120:931-944

Willems P (2014) Parsimonious rainfall-runoff model construction supported by time series processing and validation of hydrological Extremes - Part 1: Step-wise model-structure identification and calibration approach. J Hydrol 510:578-590

Willems P, Mora D, Vansteenkiste T, Taye MT, Van Steenbergen N (2014) Parsimonious rainfallrunoff model construction supported by time series processing and validation of hydrological extremes - Part 2: Intercomparison of models and calibration approaches. J Hydrol 510:591-609

Yue S, Wang C (2004) The Mann-Kendall test modified by effective sample size to detect trend in serially correlated hydrological series. Water Resour Manage 18:201-218

Zeng R, Cai X (2016) Climatic and terrestrial storage control on evapotranspiration temporal variability: Analysis of river basins around the world. Geophys Res Let 43:185-195 
Appendix A1: Structures and parameters of NAM, VHM and HBV

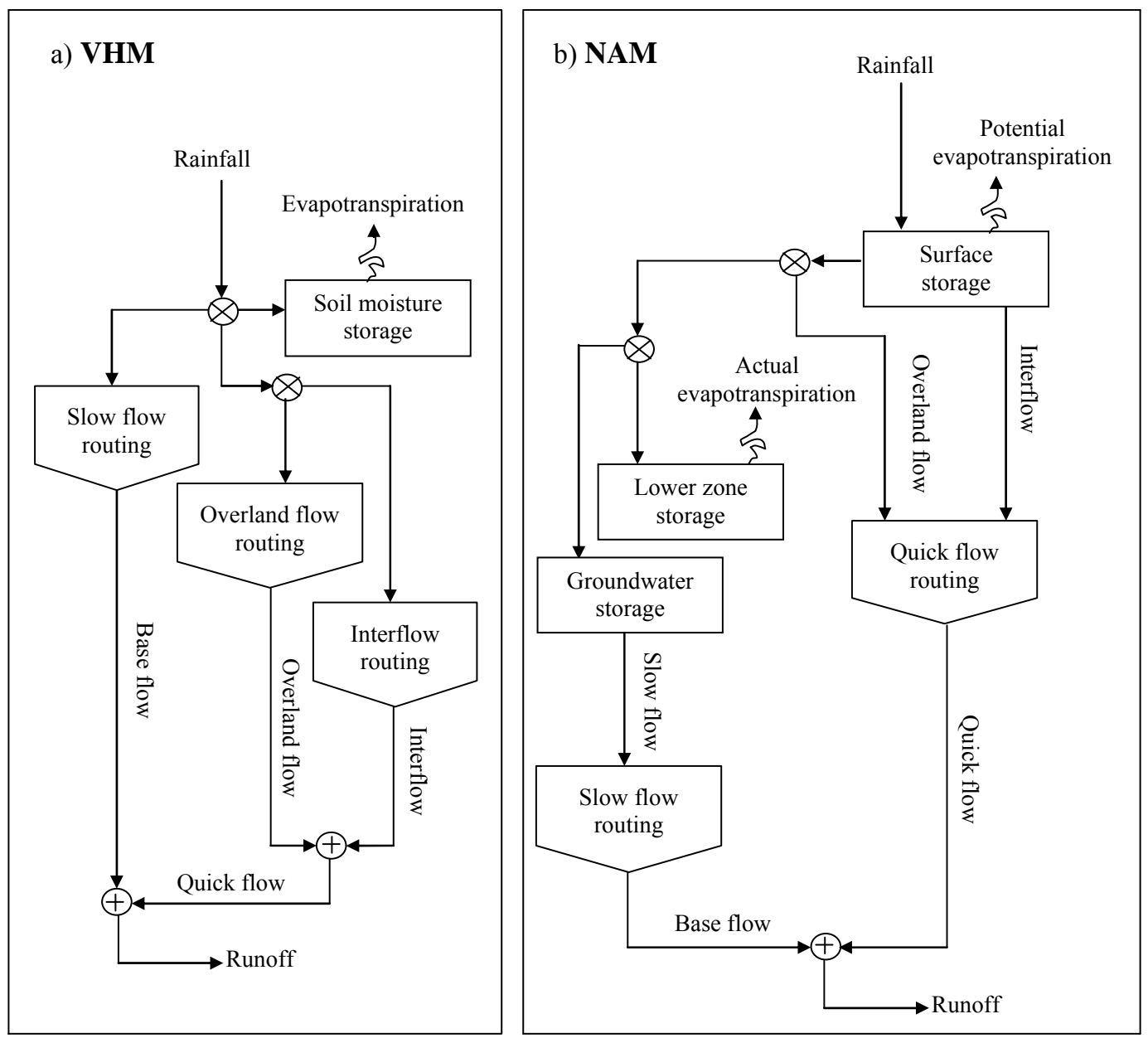

\section{c) HBV}

Inputs (Precip., Temp (T))

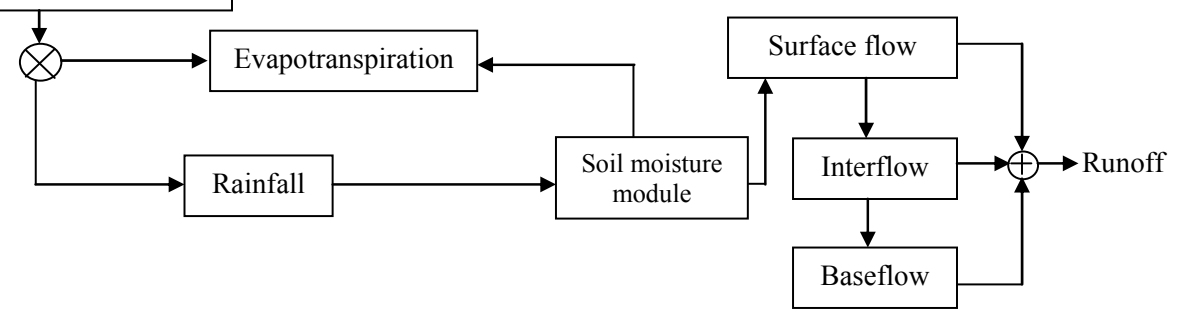

Figure A1 General processes of a) VHM, b) NAM, and c) HBV. 
Table A1: List of model parameters considered for calibration

\begin{tabular}{|c|c|c|c|}
\hline \multicolumn{2}{|l|}{$\begin{array}{ll}\text { VHM } \\
\end{array}$} & \multirow[t]{2}{*}{ Blue Nile } & \multirow[t]{2}{*}{ Kagera } \\
\hline Soil moisture (storage) sub-model & & & \\
\hline Maximum soil water content: & $U_{\max }(\mathrm{mm})$ & 1950 & 2420 \\
\hline Soil water content at maximum evapotranspiration & $U_{\text {evap }}(\mathrm{mm})$ & 300 & 964 \\
\hline Initial soil water content: & $U_{\text {init }}(\mathrm{mm})$ & 650 & 20 \\
\hline \multirow[t]{2}{*}{ Model coefficients: } & $c_{1}$ & 1.0 & 0.9 \\
\hline & $c_{2}$ & 0.67 & 0.1 \\
\hline \multicolumn{4}{|l|}{ Overland flow sub-model } \\
\hline \multirow[t]{4}{*}{ Model coefficients: } & $c_{1}$ & -11.07 & -7.09 \\
\hline & $c_{2}$ & -0.35 & 2.93 \\
\hline & $c_{3}$ & 0.55 & 0.99 \\
\hline & $c_{4}$ & 3.12 & 0.82 \\
\hline \multicolumn{4}{|l|}{ Interflow sub-model } \\
\hline \multirow[t]{4}{*}{ Model coefficients: } & $c_{1}$ & -8.99 & -9.3 \\
\hline & $c_{2}$ & -1.33 & 0.43 \\
\hline & $c_{3}$ & -0.15 & 0.65 \\
\hline & $c_{4}$ & 3.12 & 3.32 \\
\hline \multicolumn{4}{|l|}{ Flow routing recession constant } \\
\hline Base flow: & $K_{\mathrm{B}}($ day $)$ & 120 & 50 \\
\hline Interflow: & $K_{\mathrm{I}}$ (day) & 40 & 40 \\
\hline Overland flow: & $K_{\mathrm{O}}$ (day) & 20 & 20 \\
\hline \multicolumn{4}{|l|}{ HBV Model } \\
\hline Shape coefficient & $\beta(-)$ & 4.32 & 1.04 \\
\hline Field capacity & $F_{\mathrm{C}}(\mathrm{mm})$ & 171.52 & 1058.65 \\
\hline Soil permanent wilting point & $P_{\mathrm{wp}}(\mathrm{mm})$ & 97.63 & 130.08 \\
\hline Near surface flow storage coefficient & $K_{0}\left(\right.$ day $\left.^{-1}\right)$ & 0.08 & 0.06 \\
\hline Threshold water level & $T_{W L}(\mathrm{~mm})$ & 2.23 & 2.27 \\
\hline Interflow storage coefficient & $K_{1}\left(\right.$ day $\left.^{-1}\right)$ & 0.03 & 0.05 \\
\hline Baseflow storage coefficient & $K_{2}\left(\right.$ day $\left.^{-1}\right)$ & 0.02 & 0.02 \\
\hline Percolation storage coefficient & $K_{\mathrm{p}}\left(\right.$ day $\left.^{-1}\right)$ & 0.04 & 0.11 \\
\hline \multicolumn{4}{|l|}{ NAM Model } \\
\hline Maximum soil water content in the surface storage & $U_{\max }(\mathrm{mm})$ & 40 & 0.72 \\
\hline Maximum soil water content in lower zone storage & $L_{\max }(\mathrm{mm})$ & 250 & 0.25 \\
\hline Time constant for overland flow & $C Q_{\mathrm{OF}}($ day $)$ & 0.3 & 0.01 \\
\hline Time constant for interflow & $C K_{\mathrm{IF}}$ (day) & 600 & 20 \\
\hline Time constant for overland and interflow routing & $C K_{1,2}$ (day) & 34 & 400 \\
\hline Time constant for baseflow & $C K_{\mathrm{BF}}$ (day) & 4000 & 3980 \\
\hline Threshold for overland flow & $T_{\mathrm{OF}}$ & 0.23 & 0.2 \\
\hline Threshold for interflow & $T_{\mathrm{IF}}$ & 0.1 & 0.5 \\
\hline Threshold for groundwater recharge & $T_{\mathrm{G}}$ & 0.2 & 0.4 \\
\hline
\end{tabular}

